HYDROFLUORIC ACID SEPARATION OF CU AND PB, ETC.

\title{
THE USE OF HYDROFLUORIC ACID IN THE SEPARATION OF COPPER AND LEAD FROM TIN AND ANTIMONY BY MEANS OF THE ELECTRIC CURRENT.
}

\author{
BY LEROY W. MCCAY.
}

Received July 22, 1914.

A few years ago I published in THIS JourNaL ${ }^{1}$ a paper on a method for separating antimony from tin. The method is based on the fact that when antimonious oxide and stannic oxide are present in a hydrochloric or sulfuric acid solution containing some hydrofluoric acid, the introduction of a stream of hydrogen sulfide into the solution occasions a precipitation of antimonious sulfide only. If the antimony be in the higher state of oxidation and sufficient hydrofluoric acid be present it undergoes at first no change when its solution is treated with hydrogen sulfide. On continued action of the gas, the solution becomes slightly turbid from the separation of a small amount of sulfide of antimony, but this turbidity disappears at once when the solution is warmed. Copper and lead and a number of other heavy metals in hydrofluoric acid solution behave like antimonious antimony; they are thrown down completely by hydrogen sulfide.

The analogy between the behavior of solutions of the metals when treated with hydrogen sulfide and when subjected to the action of the electric current led me sometime ago to the belief that from a hydrofluoric acid solution containing both antimony and tin in the higher states of oxidation, the electric current would precipitate neither metal. Such, indeed, turns out to be the case. If copper, or lead, or both, be present along with the antimonic antimony and stannic tin, and the solution be a nitrohydrofluoric acid one, the copper is deposited at the cathode, the lead as the peroxide at the anode.

There can be no doubt but that other heavy metals can be separated from tin and antimony in a similar way.

Those who have had much to do with the chemistry of tin and antimony are familiar with the ease with which their compounds undergo hydrolysis. Particularly marked is this phenomenon in the case of salts of antimony. The presence of hydrofluoric acid, however, even in comparatively small amounts, inhibits entirely all tendency on the part of these two metals to form insoluble basic compounds. We can dilute a tin or antimony solution containing a little hydrofluoric acid indefinitely without the resulting liquids becoming turbid.

Nitric acid converts tin into insoluble metastannic acid, antimony into a mixture of antimonious and antimonic oxides which are almost insoluble in the concentrated as well as in the dilute acid. If, however, to the nitric acid a little hydrofluoric acid be added we obtain the best of all solvents for antimony and tin and their alloys. Dilute nitric acid

\footnotetext{
${ }^{1}$ 31, 373 (I909).
} 
( $1: 4$ ) contaning a small amount of hydrofluoric acid will, when gently warmed, dissolve in less than 5 minutes over one gram of a tin-antimony alloy, provided the material be in a finely divided condition.

It matters not how rich the alloys are in tin or lead, the resulting solutions are clear and limpid. In all my work I use as a solvent $25^{-50} \mathrm{cc}$. of dilute nitric acid $(1: 4)$ to which $5 \mathrm{cc}$. of $48 \%$ hydrofluoric acid ${ }^{2}$ have been added. Of course, the solutions are made in platinum. In the circumstances, all the tin, but only a part of the antimony, is converted into the higher state of oxidation. To complete the oxidation of the antimony, a saturated solution of potassium bichromate has proved best. I add it drop by drop with constant stirring until the pure green color of the warm solution takes on a slight yellowish green tint. The stirring is done with a platinum spatula tied to the end of a short stick. The chromic salt and small excess of chromic acid have no influence on the separation of the copper and lead from the tin and antimony, or on their subsequent determination. It is an interesting fact that, in the separation of copper from tin, a little platinum is dissolved at the anode and partially reprecipitated along with the copper at the cathode. The amount dissolved is variable, but seems to increase with the amount of tin present. It appears in the form of a black powder, or very thin film, when the copper deposit is dissolved in nitric acid. The film can be readily removed by gently rubbing the surface of the dish with a bit of rubber on the end of a glass rod. The amount, so far as the eye is concerned, appears to be considerable, and yet when the powder is filtered off, ignited and weighed, it rarely amounts to more than half a milligram. I have found that by first coating the anode with a film of lead peroxide the copper comes down free from platinum. Since, however, any platinum in the copper can be determined rapidly and with great accuracy, I do not think we gain anything by using an anode coated with lead peroxide. The current from one or two storage cells was employed in my work.

\section{Experimental.}

Separation of Copper from Tin.-The copper solution used contained $20.00 \mathrm{I} g$. purest blue vitriol in a liter of water.

Calculated: $25 \mathrm{cc}=0.1274 \mathrm{Cu}$; found: $25 \mathrm{cc}$. $=0.1275 \mathrm{Cu}$.

The tin used was a well-known German firm's best, and in order that the solvent might attack it most readily I had the machinist convert it into thin turnings. The weighed sample of tin was placed in an ordinary Classen dish, the requisite amount of solvent added, the dish covered with a piece of platinum foil, and the liquid very gently heated. When solution was complete a known volume of the blue vitriol solution was run in,

'Satisfactory results have been recently obtained by using smaller amounts of hydrofluoric acid. 
the liquid diluted to I Io $\mathrm{cc}$. and electrolyzed over night with a current strength of $0.25 \mathrm{~A}$. The liquid over the deposit was siphoned off with a short piece of black rubber tubing upon which the hydrofluoric acid has no action. The washing was done in the usual way, water being poured into the dish and siphoned off until the needle of the ammeter dropped to zero, the main liquid and washings being trapped in a large ceresin beaker.

\begin{tabular}{llll}
\multicolumn{2}{c}{$\begin{array}{c}\text { Copper taken. } \\
\text { Gram. }\end{array}$} & $\begin{array}{c}\text { Tin taken. } \\
\text { Gram. }\end{array}$ & $\begin{array}{c}\text { Copper found (Cor. for Pt). } \\
\text { Gram. }\end{array}$ \\
$(1) \ldots \ldots \ldots \ldots \ldots \ldots \ldots \ldots$ & 0.1020 & 0.2043 & 0.1015 \\
$(2) \ldots \ldots \ldots \ldots \ldots \ldots \ldots$ & 0.1275 & 0.3950 & 0.1274 \\
$(3) \ldots \ldots \ldots \ldots \ldots \ldots \ldots$ & 0.1275 & 0.5014 & 0.1274 \\
$(4) \ldots \ldots \ldots \ldots \ldots \ldots \ldots$ & 0.1275 & 0.5016 & $0.1276^{1}$
\end{tabular}

Separation of Copper from Antimony.-The separation was carried out in a manner similar to that employed in separating copper from tin. Before introducing the current, however, all antimonious oxide was oxidized to antimonic oxide with a concentrated solution of potassium bichromate. In (3) I detected a trace of platinum in the copper. The current ran over night. Current strength, $0.25 \mathrm{~A}$.

\begin{tabular}{|c|c|c|c|}
\hline & $\begin{array}{c}\text { Copper taken. } \\
\text { Gram. }\end{array}$ & $\begin{array}{c}\text { Antimony taken. } \\
\text { Gram. }\end{array}$ & $\begin{array}{l}\text { Copper found. } \\
\text { Gram. }\end{array}$ \\
\hline (I). & 0.1020 & o. I 993 & 0.1018 \\
\hline (2). & O. 1275 & 0.2102 & 0.1273 \\
\hline (3).. & o. 1275 & 0.5008 & O.1274 \\
\hline
\end{tabular}

In order to see how accurate the results for copper would be when both tin and antimony were present, I dissolved in the platinum dish in $50 \mathrm{cc}$. of the nitrohydrofluoric acid various amounts of a tin-antimony alloy containing from 0.13 to $0.14 \%$ copper, oxidized the $\mathrm{Sb}^{\mathrm{III}}$ to $\mathrm{Sb}^{\mathrm{V}}$ with potassium bichromate, added $25 \mathrm{cc}$. of the standard blue vitriol solution and brought the volume to I IO cc. From the weight of the copper found in each case, the amount of the metal present in the quantity of alloy taken was deducted. The alloy was analyzed several years ago with the following results:

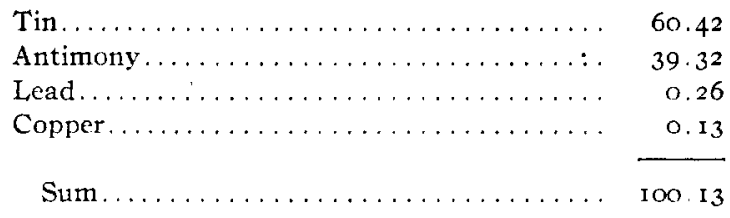

Since the lead separated as the peroxide on the spiral anode I also determined it in each case. The current ran over night. Current strength, $0.25 \mathrm{~A}$.

1 Anode coated with $\mathrm{PbO}_{2}$. 


\begin{tabular}{|c|c|c|c|c|}
\hline & $\begin{array}{l}\text { Copper taken. } \\
\text { Gram. }\end{array}$ & $\begin{array}{l}\text { Alloy taken. } \\
\text { Grams. }\end{array}$ & $\begin{array}{l}\text { Copper found (Cor. } \\
\text { for } P t \text { ). Gram. }\end{array}$ & $\begin{array}{l}\text { Iead found in } \\
\text { alloy. Per cent. }\end{array}$ \\
\hline$(\mathrm{I}) \ldots$ & .0 .1275 & 0.5001 & O.I 274 & 0.26 \\
\hline (2). & 0.1275 & 1.0005 & 0.1275 & 0.27 \\
\hline$(3) \ldots$ & o. 1275 & I.OOIO & 0.1276 & 0.26 \\
\hline$(4) \ldots \ldots \ldots$ & 0.1275 & I.OIOO & o. 1277 & 0.25 \\
\hline
\end{tabular}

Separation of Lead from Tin and Antimony.-The solutions contained $20 \mathrm{cc}$. conc. nitric acid and $5 \mathrm{cc} .48 \%$ hydrofluoric acid. The large amount of nitric acid is necessary in order to inhibit the separation of metallic lead at the cathode. The antimony present in the lower state of oxidation was converted into the higher state by means of chromic acid and the volume of the solution was always brought to I ro cc. The lead peroxide was deposited in a Classen dish roughened by means of a sand blast. Since this dish is made the anode, and a large surface is consequently exposed to the action of oxygen, which in the presence of hydrofluoric acid has a slight action on platinum, it may lose in weight during the electrolysis, and should, therefore, be reweighed after dissolving out the peroxide. Hot, dilute nitric acid, containing considerable oxalic acid dissolved in it, is well adapted for removing the peroxide from the dish. Dilute nitric acid to which a little ordinary hydrogen peroxide, free from hydrochloric acid, has been added serves the purpose equally well.

My first results for lead were much too high, in spite of the fact that I could detect no tin or antimony in the peroxide deposits. It is a well recognized fact that when lead is determined as peroxide, with the electric current, the results are apt to be high, and this is thought by most chemists to be due to the presence of water which is not completely expelled at I $90-200^{\circ}$. My results, however, were almost $2 \mathrm{mg}$. in excess of what they should be. Thus far I have been unable to account for these high figures.

The lead solution used as a standard contained $6.0004 \mathrm{~g}$. pure lead nitrate in a liter.

$$
\begin{aligned}
& \begin{array}{c}
\text { Calculated. } \\
\text { Gram. }
\end{array} \\
& 25 \mathrm{cc} .=0.0938
\end{aligned}
$$

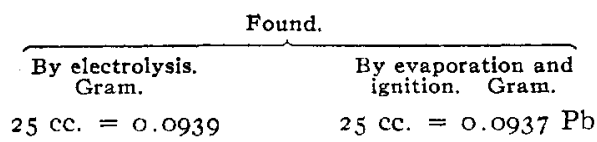

Separation of Lead from Tin.-The current ran over night. Current strength, $0.3 \mathrm{~A}$.
(I) $\ldots \ldots \ldots, 0.0938$
(2) $\ldots \ldots \ldots \ldots, 0.0938$
(3) $\ldots \ldots \ldots \ldots, 0.0938$
Average, $0.0956 \mathrm{gram}$.
$0.0956 \mathrm{~g}$. found $-0.0938 \mathrm{~g}$. taken $=0.0018 \mathrm{~g}$. overweight.
Tin taken.
Lead found
$0.5014 \quad 0.0956$
$0.5084 \quad 0.0955$
$0.5102 \quad 0.0957$

In separating the metal from antimony the same high results were obtained. A determination of lead in dilute nitrohydrofluoric acid solution, 
when no tin was present, gave me the figure 0.0957 . Since a satisfactory result was always obtained when no hydrofluoric acid was present, it seems reasonable to assume that the overweights of the deposits are due to the presence, in them, of fluorine in some form. Thus far, however, I have been unable to detect any with certainty. The error can be eliminated, and results obtained equal almost in accuracy to those arrived at when lead is determined as peroxide in nitric acid alone, by proceeding as follows: After siphoning off the supernatant liquid and washing a deposit until the needle of the ammeter stands at zero, $20 \mathrm{cc}$. conc. nitric acid are again poured into the dish, the dish is filled with water until the peroxide is just covered, and the current reversed. In a few minutes the solution is complete, the current is then again reversed and the lead reprecipitated as peroxide. Using a current strength of $0.5 \mathrm{~A}$., the time necessary for complete reprecipitation is from $4-5$ hours.

Here are some results obtained by following the modification just described:

\begin{tabular}{|c|c|c|c|}
\hline & $\begin{array}{c}\text { Lead taken. } \\
\text { Gram. }\end{array}$ & $\begin{array}{c}\text { Tin taken. } \\
\text { Gram. }\end{array}$ & $\begin{array}{l}\text { Lead found. } \\
\text { Gram. }\end{array}$ \\
\hline$(\mathbf{I}) \ldots \ldots \ldots \ldots$ & 0.0938 & 0.2015 & 0,0935 \\
\hline$(2) \ldots \ldots \ldots \ldots$ & 0.0938 & 0,2625 & 0.0938 \\
\hline (3) $\ldots$ & 0.0938 & 0.3025 & 0.0939 \\
\hline (4)... & 0.0938 & 0.4987 & 0.0937 \\
\hline (5). . & 0.0938 & 0.5036 & 0.0939 \\
\hline$(6) \ldots \ldots \ldots \ldots$ & 0.1876 & 0.5168 & 0.1881 \\
\hline
\end{tabular}

The next determinations show that all the tin taken is present in the liquid siphoned off from the first peroxide deposit, and that from the standpoint of ordinary analysis no appreciable amount can be included in the $\mathrm{PbO}_{2}$.

\begin{tabular}{|c|c|c|c|c|}
\hline & $\begin{array}{l}\text { Lead taken. } \\
\text { Gram. }\end{array}$ & $\begin{array}{c}\text { Tin taken. } \\
\text { Gram. }\end{array}$ & $\begin{array}{l}\text { Lead found. } \\
\text { Gram. }\end{array}$ & $\begin{array}{l}\text { Tin found. } \\
\text { Gram. }\end{array}$ \\
\hline & 0.1876 & o. I6I4 & 0.1875 & o. 1623 \\
\hline & 0.1876 & 0.2994 & o. 1881 & 0.2995 \\
\hline & 0.1876 & 0.5169 & o. 1875 & 0.5170 \\
\hline
\end{tabular}

I determined the tin by ađding to the solution containing it ro cc. conc. sulfuric acid, evaporating as far as possible in platinum on the water bath, heating the residue to strong fuming to expel the hydrofluoric acid, cooling, and pouring the liquid into a liter of water. The tin was weighed as stannic oxide.

Separation of Lead from Antimony. - The details to be observed in separating lead from antimony will be evident from what has already been said. It should be remembered, however, that before introducing the current all antimony present in the lower state of oxidation must be brought to the higher state with a solution of potassium bichromate. The deposits first obtained were redissolved by reversing the current, and the results for the lead calculated from the weights of the reprecipitated peroxide 
(see the Separation of Lead from Tin). Current strength for first precipitation (over night), $0.25 \mathrm{~A}$, for second (4-5 hrs.), $0.5 \mathrm{~A}$.
Lead taken.
Gram.
Antimony taken.
Gram.
Lead found.
Gram;
Antimony found.
Gram.
(I) ..... 0.0750
O. I 201
0.0753
0.1200
(2) ..... 0.0938
0.1402
0.0935
0.1411
(3) ..... 0.0938
0.2100
0.0936
0.2099
(4) ...... 0.1876
o. 1209
0.1871
o. 1208

In each case the liquids and washings from the first precipitations of the lead as peroxide were treated with Io cc. of conc. sulfuric acid and evaporated on the water bath in platinum as far as possible. The residues were heated to strong fuming, the dish was covered, a piece of pure sulfur dropped in and the sulfuric acid boiled as gently as possible for 20 minutes. The antimony, now in the lower state of oxidation, was then determined volumetrically with potassium permanganate according to Kessler's method. ${ }^{3}$

Excellent results have been obtained by dissolving the lead peroxide deposits first obtained in about ro cc. dilute nitric acid to which 5 cc. ordinary hydrogen peroxide free from hydrochloric acid were added, transferring the solution to a quartz or porcelain dish, adding $5 \mathrm{cc}$. conc. sulfuric acid, evaporating as far as possible on the water bath, heating the residue to strong fuming, and determining the lead as the sulfate. The salt was collected and ignited in a Neubauer crucible.
I,ead nitrate taken.
Lead cal.
Alloy taken."
Lead found.*
(I) . . . . 0.2103
o. 1315
Gram.
Gram.
(2) $\ldots \ldots, 0.3002$
0.1877
0.3900
0.1316
(3) ..... 0.6007
0.3756
0.4993
○. 1878
0.5005
$0.375^{2}$

Some experiments having shown, at this stage of the work, that lead peroxide is attacked quite slowly by dilute nitrohydrofluoric acid, I broke the current in all the last three separations as soon as precipitation was complete, and at once poured off the liquid above the deposits. The results are perfectly satisfactory, and prove that it is not necessary that the deposits should be washed while the current is still passing. This is inportant, as we are not required to evaporate such large volumes of liquid, in case a determination of tin or antimony is desired.

The copper and lead in a white metal, very homogeneous in composition, have been determined with marked success according to this hydrofluoric acid method. About $0.5 \mathrm{~g}$. of the finely divided material was employed in each case. The lead peroxide first deposited was transformed into the sulfate, according to the directions above given, and weighed in

1 Pogg. Ann., I18, I7 (1863). See also Fresenius' Quant. Analyse (1875), B. I., p. 360 .

${ }^{2}$ The composition of this alloy is given on p. 2377 .

Corrected for the $0.26 \%$ present in the alloy. 
this form. From the liquid poured off from the lead peroxide the copper was precipitated, after the excess of acid had been neutralized with ammonia.

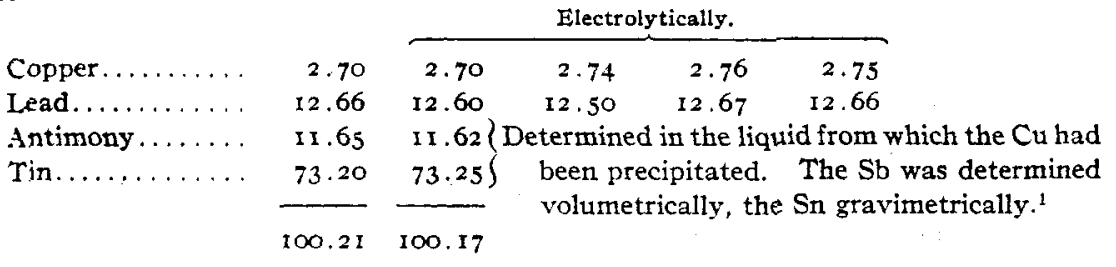

From a dilute nitrohydrofluoric acid solution, copper can be separated from tungsten, and mercury and silver from tin and antimony. My assistant, Mr. N. H. Furman, finds that the results obtained in separating mercury from tin and antimony are fully as exact as those arrived at in separating copper from these metals. Attempts are being made to separate and determine other metals by means of the current when they are present in solutions containing hydrofluoric acid.

PRINCETON, N. J.

\section{THE CONSTITUTION OF ALUMINATES. II.}

\section{BY EDWARD G. MAFIN.}

Received August 18, 1914.

In a recent paper by Blum, ${ }^{2}$ entitled "Constitution of Aluminates," criticism was made of an earlier paper bearing the same title ${ }^{3}$ by Mahin, Ingraham and Stewart. Inasmuch as the author seems to have entirely misinterpreted a part of the experimental work described in the first paper, and the deductions therefrom, it seems necessary to correct these impressions.

Mahin, Ingraham and Stewart concluded that the hypothesis of aluminates having definite formulas had not been substantiated by any of the earlier work and that sufficient attention had not been 'given to the colloidal properties of aluminium hydroxide, as bearing upon its solubility in solutions of bases. Their supposition was that by adsorption of hydroxyl ions the aluminium hydroxide may be, to a considerable extent, maintained in a dispersed condition, molecular aggregates acquiring thereby a negative charge which has caused these aggregates to be mistaken for definite anions, because of their behavior when a current of electricity is passed through the solution of "aluminate."

This possibility seemed to be favored by the results of experiments upon the heat of solution of aluminium hydroxide in bases, upon the pre-

1 The metals were separated according to the method described in THIS JourNaL. 31,373 (1909).

2 ThIs JOURNaL, 35, 1499 (1913).

'Ibid., 35, 30 (1913). 